\title{
Internationally harmonized certified reference materials and proficiency testings for pesticide residue analysis
}

\author{
Takamitsu Otake ${ }^{1}$ and Takashi Yarita ${ }^{2, *}$ \\ ${ }^{1}$ National Metrology Institute of Japan (NMIJ), National Institute of Advanced Industrial Science and Technology (AIST), 1-1-1 Umezono, Tsukuba, \\ Ibaraki 305-8563, Japan \\ ${ }^{2}$ College of Agriculture, Ibaraki University, 3-21-1 Chuo, Ami, Inashiki, Ibaraki 300-0321, Japan
}

(Accepted May 28, 2021)

Matrix certified reference materials (CRMs) and proficiency testings (PTs) are effective for evaluation of the quality of analytical results. The National Metrology Institute of Japan has developed five kinds of CRMs and has provided eight PTs so far for the quantification of pesticide residues in foods. Target pesticides were sprayed on growing crops, and the harvests were used for the preparation of CRMs and PT samples. In most cases, multiple analytical methods based on isotope dilution mass spectrometry were used to ensure the reliability of certified values (for CRMs) and reference values (for PT samples). These activities were carried out with corresponding to the international standards such as ISO 17034 and ISO/IEC 17043. An overview of the development of CRMs and the implementation of PTs is described, with some examples.

Keywords: certified reference material, proficiency test, quality assurance/quality control, pesticide residue, isotope dilution mass spectrometry, international standards.

\section{Introduction}

It is important to analyze the levels of pesticides in foods to monitor for contamination and to investigate the relationship between exposure and health risks. The complex sample pretreatments and highly selective instrumental analyses involved in analyzing pesticide residues in food necessitate quality control to obtain accurate analytical results. ${ }^{1)}$ The quality of analytical results can be evaluated effectively using matrix certified reference materials (CRMs) and/or proficiency testings (PTs), which are also useful for improving measurement quality and resolving analytical problems. ${ }^{1-3)}$ Testing recovery by adding compounds (e.g., surrogates) to matrix samples such as blank food (spiking), is widely used for the evaluation of analytical methods in many testing laboratories. However, solute-matrix interactions of native pesticides in food samples may render this approach unsuitable. Therefore, the use of CRMs is useful be-

\footnotetext{
* To whom correspondence should be addressed.

E-mail: takashi.yarita.fsa@vc.ibaraki.ac.jp

Published online August 31, 2021
}

(c) BY-NC-ND $\odot$ Pesticide Science Society of Japan 2021. This is an open access article distributed under the Creative Commons Attribution-NonCommercial-NoDerivatives 4.0 International (CC BY-NC-ND 4.0) License (https://creativecommons.org/licenses/by-nc-nd/4.0/) cause the behavior of analytes in CRMs is more similar to those in actual samples. PT is recommended for testing and calibration laboratories in the International Standards Organization (ISO)/International Electrotechnical Commission (IEC) 17025: 2017.4) The Guideline 27 of Codex Alimentarius also requires laboratories involved in the import and export control of foods to participate in appropriate PTs. ${ }^{5)}$

The National Metrology Institute of Japan (NMIJ) has developed five kinds of $\mathrm{CRMs}^{6-9)}$ and provided eight $\mathrm{PTs}^{1,10-13)}$ so far for the quantification of pesticide residues in foods. These are summarized in Tables 1 and 2. This type of CRM has not been developed previously. The target pesticides selected are widely used in Japan. For CRMs, we selected matrices that were as rich in variety as possible. On the other hand, grains such as brown rice, wheat, and soybean were mainly selected as food matrices for PTs because other PTs have hardly been performed using grains despite large amounts of grain being consumed worldwide. Because our material samples used for CRMs and PTs contain the target pesticides added by spraying, the method performance, including extraction efficiency, can be evaluated accurately. NMIJ analyzed samples using isotope dilution mass spectrometry (IDMS) to provide highly reliable values for the pesticides contained in CRMs and PT samples, which is a potential primary measurement method. ${ }^{14-17)}$ In this paper, an overview is given of the development of CRMs and the implementation of PTs. 
Table 1. Comparison of certified concentrations and maximum residue limits for five NMIJ CRMs

\begin{tabular}{|c|c|c|c|c|c|}
\hline \multirow[b]{2}{*}{ Pesticides } & \multicolumn{5}{|c|}{ Matrices (CRM No., Distributed year) } \\
\hline & $\begin{array}{c}\text { Brown rice } \\
(7504-\mathrm{a}, 2009)\end{array}$ & $\begin{array}{l}\text { Green onion } \\
(7507-\mathrm{a}, 2011)\end{array}$ & $\begin{array}{c}\text { Cabbage } \\
(7508-\mathrm{a}, 2011)\end{array}$ & $\begin{array}{c}\text { Apple } \\
(7510-a, 2012)\end{array}$ & $\begin{array}{c}\text { Soybean } \\
(7509-\mathrm{a}, 2013)\end{array}$ \\
\hline Chlorpyrifos (MRLs) & & & $6.9 \pm 2.4(0.05)$ & & $0.0111 \pm 0.0032(0.3)$ \\
\hline Cypermethrin (MRLs) & & $3.98 \pm 0.91(5)$ & & $1.55 \pm 0.81(2)$ & \\
\hline Diazinon (MRLs) & & $0.96 \pm 0.19(0.1)$ & & $2.28 \pm 0.82(0.3)$ & $0.0217 \pm 0.0032(0.05)$ \\
\hline Etofenprox (MRLs) & $0.19 \pm 0.05(0.5)$ & $13.9 \pm 1.3(2)$ & & & \\
\hline Fenitrothion (MRLs) & $0.109 \pm 0.017(0.2)$ & $4.41 \pm 0.29(0.3)$ & $2.41 \pm 0.45(0.01)$ & $3.14 \pm 0.79(0.5)$ & $0.088 \pm 0.021(0.05)$ \\
\hline Permethrin (MRLs) & & $7.14 \pm 0.59(2)$ & $5.75 \pm 0.68(5)$ & $2.81 \pm 0.70(2)$ & $0.0201 \pm 0.0043(0.05)$ \\
\hline
\end{tabular}

The values represent the certified concentrations \pm expanded uncertainties, and the unit of the values is $\mathrm{mg} / \mathrm{kg}$; the expanded uncertainties were determined by using a coverage factor $k=2$, corresponding to a $95 \%$ confidence interval. The grayed out area means non-target pesticide for certification; MRLs=maximum residue limits, which are stipulated in a Positive List System for Agricultural Chemical Residues in Foods introduced in May 2006 in Japan. The certified concentrations were obtained by NMIJ analysis. The MRL for fenitrothion in cabbage (7508-a) represents the uniform limit $(0.01 \mathrm{mg} / \mathrm{kg})$ determined by the Ministry of Health, Labour and Welfare, Japan.

\section{Quality management system of NMIJ}

To ensure international harmonization of the developed CRMs, NMIJ has a quality management system based on ISO 17034 ${ }^{18)}$ and ISO/IEC 17025, ${ }^{4}$ which is accredited by the National Institute of Technology and Evaluation (NITE). CRM certification has been carried out according to the technical requirements of ISO Guide $35 .{ }^{19)}$ On the other hand, the PTs have been conducted in according to ISO/IEC $17043 .{ }^{20)}$ The statistical treatment of the dataset in these PTs has been carried out based on ISO $13528 .^{21)}$

\section{Preparation of samples for CRMs and PTs ${ }^{1,6-13)}$}

Using samples containing the target pesticides allows a necessary examination of the analytical method, including extraction efficiency. Therefore, the raw materials, which were sprayed with various target pesticides as shown in Tables 1 and 2, were used for the preparation of CRMs and PT samples. Following harvesting, the samples were freeze-pulverized or freeze-dried, homogenized, placed into clean glass bottles, and sterilized with ${ }^{60} \mathrm{Co} \gamma$-radiation (as needed, $15 \mathrm{kGy}$ ). Until analysis, samples were stored in the dark at a temperature between -20 and $-30^{\circ} \mathrm{C}$. Comparisons of the maximum residue limit (MRL) concentrations ${ }^{22)}$ with the contained concentration (analyzed by the

Table 2. Comparison of reference concentrations and maximum residue limits for PT samples

\begin{tabular}{|c|c|c|c|c|c|c|c|c|}
\hline \multirow[b]{2}{*}{ Pesticides } & \multicolumn{8}{|c|}{ Matrices (Survey year) } \\
\hline & $\begin{array}{c}\text { Soybean } \\
(2012)\end{array}$ & $\begin{array}{l}\text { Brown rice } \\
(2013)\end{array}$ & $\begin{array}{c}\text { Husked wheat } \\
(2014)\end{array}$ & $\begin{array}{c}\text { Brown rice } \\
(2015)\end{array}$ & $\begin{array}{c}\text { Soybean } \\
(2016)\end{array}$ & $\begin{array}{c}\text { Brown rice } \\
(2017)\end{array}$ & $\begin{array}{c}\text { Husked wheat } \\
(2018)\end{array}$ & $\begin{array}{c}\text { Green onion } \\
(2019)\end{array}$ \\
\hline $\begin{array}{l}\text { Chlorpyrifos } \\
\text { (MRLs) }\end{array}$ & $\begin{array}{c}0.0116 \pm 0.0016 \\
(0.3)\end{array}$ & & & & $\begin{array}{c}0.0316 \pm 0.0008 \\
(0.3)\end{array}$ & & & \\
\hline $\begin{array}{l}\text { Diazinon } \\
\text { (MRLs) }\end{array}$ & $\begin{array}{c}0.0218 \pm 0.0014 \\
(0.05)\end{array}$ & & $\begin{array}{c}0.0660 \pm 0.0015 \\
(0.01)\end{array}$ & & & & & \\
\hline $\begin{array}{c}\text { Etofenprox } \\
\text { (MRLs) }\end{array}$ & & $\begin{array}{c}0.142 \pm 0.009 \\
(0.5)\end{array}$ & $\begin{array}{c}0.123 \pm 0.0047 \\
(0.5)\end{array}$ & $\begin{array}{c}0.236 \pm 0.008 \\
(0.5)\end{array}$ & & $\begin{array}{c}0.163 \pm 0.004 \\
(0.5)\end{array}$ & $\begin{array}{l}0.273 \pm 0.011 \\
(0.5)\end{array}$ & \\
\hline $\begin{array}{l}\text { Fenitrothion } \\
\text { (MRLs) }\end{array}$ & $\begin{array}{c}0.0879 \pm 0.0116 \\
(0.05)\end{array}$ & $\begin{array}{c}0.158 \pm 0.004 \\
(0.2)\end{array}$ & $\begin{array}{c}0.284 \pm 0.010 \\
\text { (1) }\end{array}$ & $\begin{array}{c}0.0986 \pm 0.0034 \\
(0.2)\end{array}$ & $\begin{array}{c}0.141 \pm 0.006 \\
(0.05)\end{array}$ & $\begin{array}{c}0.129 \pm 0.004 \\
(0.2)\end{array}$ & $\begin{array}{c}0.618 \pm 0.021 \\
\text { (1) }\end{array}$ & $\begin{array}{c}1.37 \pm 0.040 \\
(0.3)\end{array}$ \\
\hline $\begin{array}{l}\text { Isoprothiolane } \\
\text { (MRLs) }\end{array}$ & & $\begin{array}{c}1.01 \pm 0.05 \\
(10)\end{array}$ & & & & $\begin{array}{c}1.22 \pm 0.047 \\
(10)\end{array}$ & & \\
\hline $\begin{array}{r}\text { Malathion } \\
\text { (MRLs) }\end{array}$ & & & $\begin{array}{c}0.0513 \pm 0.0036 \\
(10)\end{array}$ & & & & $\begin{array}{c}0.146 \pm 0.010 \\
(10)\end{array}$ & \\
\hline $\begin{array}{l}\text { Permethrin } \\
\text { (MRLs) }\end{array}$ & $\begin{array}{c}0.0199 \pm 0.0040 \\
(0.05)\end{array}$ & & & & & & & \\
\hline $\begin{array}{l}\text { Thiamethoxam } \\
\text { (MRLs) }\end{array}$ & & & & $\begin{array}{c}0.142 \pm 0.007 \\
(0.3)\end{array}$ & & & & $\begin{array}{c}2.38 \pm 0.090 \\
(2)\end{array}$ \\
\hline
\end{tabular}

The values represent the reference concentrations \pm expanded uncertainties, and the unit of the values is $\mathrm{mg} / \mathrm{kg}$; the expanded uncertainties were determined by using a coverage factor $k=2$, corresponding to a $95 \%$ confidence interval. The grayed out area means non-target pesticide for PT; MRLs=maximum residue limits, which are stipulated in a Positive List System for Agricultural Chemical Residues in Foods introduced in May 2006 in Japan. The reference concentrations were obtained by NMIJ analysis. The MRL for diazinon in husked wheat (2014) represents the uniform limit $(0.01 \mathrm{mg} / \mathrm{kg})$ decided by the Ministry of Health, Labour and Welfare, Japan. 
NMIJ) for each CRM and PT are also shown in Tables 1 and 2, respectively. Based on these results, our materials for CRMs and PT samples were prepared at adequate concentration levels because most of the contained concentrations were $c a$. $0.1-5$ times the MRLs, although it is difficult to prepare the exact desired concentration owing to the influence of the weather. Therefore, it is considered that our samples were useful for quality assurance and quality control.

\section{Homogeneity/stability assessments ${ }^{1,6-13)}$}

Between-bottle homogeneity was assessed based on ISO Guide $35^{19)}$ by quantifying target pesticides in two subsamples taken from ten vials randomly selected from a total set of 80-330 bottles prepared for CRMs and/or PTs. Analysis of variance (ANOVA) was used to analyze the differences in the measured concentrations between the bottles. No statistically significant differences in pesticide concentrations between bottles were observed in either the CRMs or PT samples, except for permethrin and cypermethrin in apple CRM 7510-a (The inhomogeneity of these analytes was also evaluated by ANOVA and were reflected in the uncertainty of the certified value). This result indicates that the materials are sufficiently homogeneous for target pesticide analysis.

For long-term stability assessment of the candidate CRM, the concentrations were monitored on a periodic basis for about a year before the certification, using bottles stored at a temperature between -20 and $-30^{\circ} \mathrm{C}$ in the dark. If changes were detected in the concentrations of target pesticides, the uncertainties for long-term stability were included in the uncertainties of certified values in accordance with ISO guide $35 .{ }^{19)}$ In addition, after distribution, monitoring of the pesticide concentrations is regularly carried out. For each PT, the stability of the target pesticides was assessed before and after the analytical period by the participants. The results of the stability assessment indicated that the differences in concentrations were not significant.

\section{Analysis for obtaining NMIJ certified values for CRMs and reference values for PT samples ${ }^{1,6-13)}$}

To enhance the reliability of NMIJ analytical data, we participated in Comité Consultatif pour la Quantité de Matière (CCQM) comparisons to assess the analytical capabilities of National Metrology Institutes. We also conducted a collaborative study with a Japanese PT provider, that is, the Food and Drug Safety Center, Hatano Research Institute. ${ }^{23)}$ From the results of these studies, we proved the accuracy of our analytical data for the analysis of various pesticides, such as organophosphorus and pyrethroid in foods, and ensured international conformity. For example, one of the results of CCQM comparisons is shown in a previous report. $^{24)}$

In most cases, analyses for providing certified values (for CRMs) and reference values (for PT samples) were carried out based on a modified Japanese official method. In many cases, different extraction and clean-up procedures, GC injection techniques, and GC columns were applied to provide the certi- fied values (for CRMs) and reference values (for PT samples) to avoid any bias associated with a certain analytical method. The details of each procedure have been described in previous papers. ${ }^{1,6-13)}$ Pesticide quantification was performed using IDMS and a matrix-matched calibration solution. If the reference values were provided only by a modified Japanese official method, the validation was carried out by other methods such as a solidphase extraction technique with the Quick, Easy, Cheap, Effective, Rugged, and Safe (modified QuEChERS, known as "STQ" in Japan), QuEChERS methods, and other methods with IDMS.

\section{Development of $\mathrm{CRMs}^{6-9)}$}

\subsection{Certification of CRMs}

Since the preparation of samples and analysis, which are the most common processes with PTs, are described above, the remaining processes and an example of certification are described in this section.

The strategy for the development of matrix CRMs at NMIJ has been established. ${ }^{25)}$ The certified values were the weighted means of the analytical results obtained by two or more analytical methods for each pesticide, where $1 / u_{\mathrm{i}}\left(u_{\mathrm{i}}\right.$ : uncertainty of the result obtained by each method) was used as the weight (an arithmetic mean was used only for brown rice (CRM 7504-a) ${ }^{6}$ ) because a statistically significant difference in the concentration values of etofenprox between methods was observed. The uncertainties of the certified values were calculated from uncertainties due to respective factors according to the Guide to the Expression of Uncertainty in Measurement. ${ }^{26)}$ Specifically, the uncertainties of the NMIJ certified values were estimated from standard uncertainty due to analytical results (including between-method variance), instability of target pesticides, and inhomogeneity of the material. ${ }^{25)}$ The results of the evaluation for individual CRMs have been reported in previous papers. ${ }^{6-9)}$

\subsection{An example of development}

The certification of pesticide residues in green onion (CRM $7508-a)^{7)}$ is described here. The target analyte was defined by five pesticides: cypermethrin, diazinon, etofenprox, fenitrothion, and permethrin. Green onions used for CRM materials were sprayed with pesticides twice at 14 and 7 days before harvest for diazinon, fenitrothion, etofenprox, and at 10 and 3 days before harvest for cypermethrin and permethrin. The harvested green onions were prepared as described in Section 2. The certified values were determined using the results obtained by three analytical methods (two methods were used for each pesticide; the outline is shown in Fig. 1). These methods were referred to in previous studies, ${ }^{27,28)}$ and we have partly modified them. Matrixmatched calibration standards were used for quantification. Pesticides were quantified by IDMS. The concentrations between methods 1 and 2 or 3 were in good agreement with each other. The certified values are the weighted means of the analytical results obtained by the two methods for each pesticide as described above, and they are shown in Table 1. 
Method No.

Target pesticides

$\underline{\text { Extraction }}$

(Solvent)

$\underline{\text { Clean-up }}$

Measurement

Injection mode

(Column)
1

cypermethrin, diazinon, etofenprox, fenitrothion, and permethrin

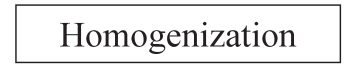

$(\mathrm{ACN})$

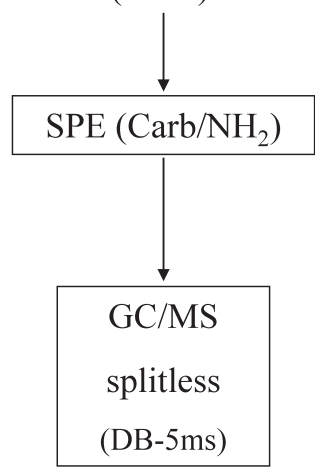

2

diazinon and fenitrothion

Homogenization

(Ace)

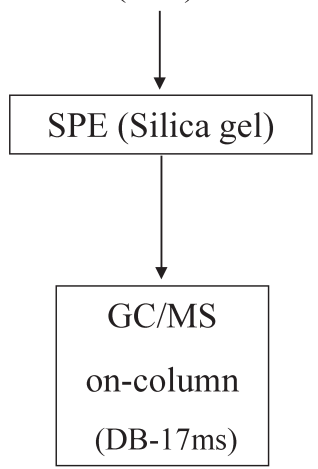

3

cypermethrin, etofenprox, and permethrin

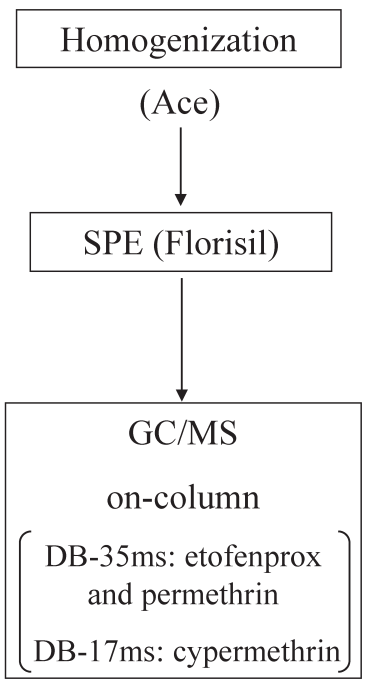

Fig. 1. Analytical scheme for the certification of pesticides in green onion (CRM 7507-a). ACN, acetonitrile; Ace, acetone; SPE, solid phase extraction; Carb/ $\mathrm{NH}_{2}$, graphite carbon/aminopropyl silanized silica gel.

\section{Implementation of $\mathrm{PTs}^{1,10-13)}$}

6.1. PT procedures and analytical methods used by PT participants

Test samples were sent by refrigerated transport to each participant. A laboratory code number and information about sample handling were delivered at the same time as a cover letter. Each participant also electronically received a report form prepared by the NMIJ and completed result reports were submitted electronically to the NMIJ. Many Japanese participants (33-89 per year, between 2012 and 2019), including testing laboratories, food manufacturers, public research organizations, and analytical instrument companies, participated in our PT.

Participants were requested to quantify target pesticides, which could be selected by the participants (any one of the target pesticides was allowable), with the method of their choice, and they analyzed for target pesticides by any of the following methods: the Japanese official multiresidue method ${ }^{27)}$; modified QuEChERS (STQ) method ${ }^{29)}$; QuEChERS ${ }^{30)}$; supercritical fluid extraction (SFE), the official Japanese method for a specific

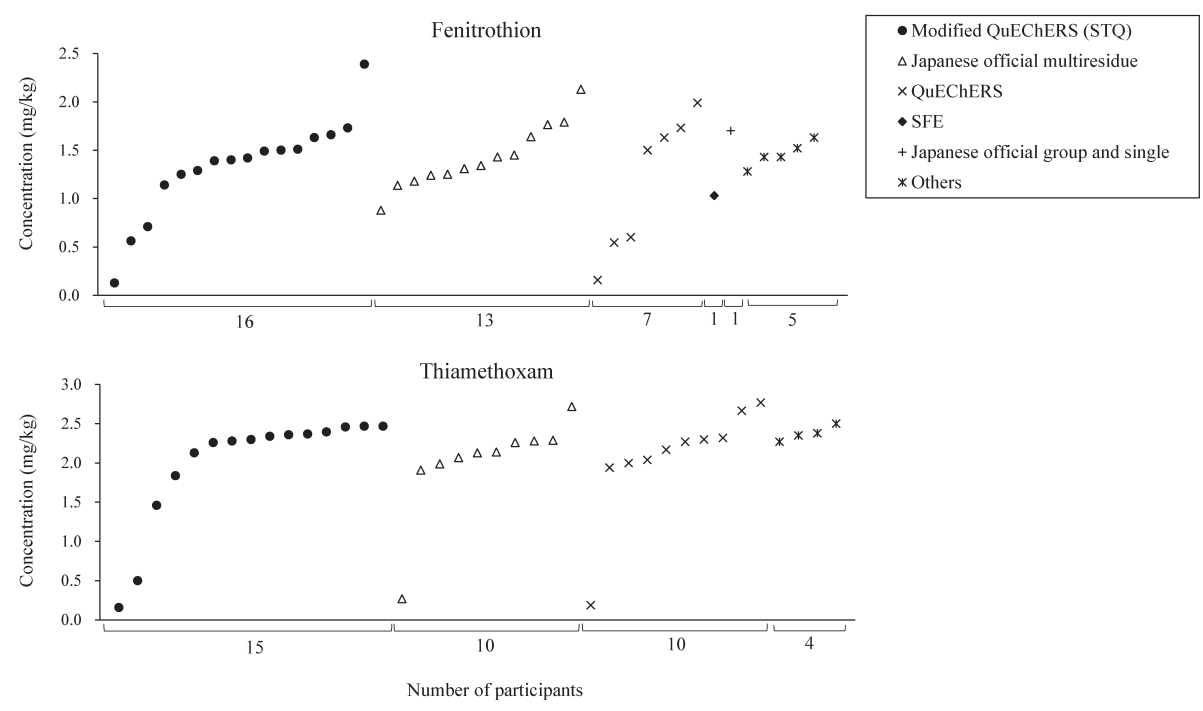

Fig. 2. Pesticide concentrations obtained by various analytical methods reported by participants in the 2019 PT. The $x$-axis represents the number of participants for each analytical method. QuEChERS: Quick, Easy, Cheap, Effective, Rugged, and Safe method; STQ: SPE technique with QuEChERS; SFE: supercritical fluid extraction; Others: original method developed by participants. 
group or pesticide ${ }^{28)}$; or an original method developed by the participants. There were no significant differences between these methods and the concentrations reported by participants, except for the results obtained by SFE (for fenitrothion in the 2018 PT, the reason for which is currently being investigated). The results obtained by each analytical method in the 2019 PT are compared in Fig. 2 as an example.

\subsection{Comparison of consensus and NMIJ reference values}

The NMIJ reference values $\left(X_{\mathrm{NMIJ}}\right)$ were up to approximately $30 \%$ greater than the corresponding consensus values for most pesticides. This can be mainly attributed to the different quantification methods used. Most participants used an external standard method to determine the concentration values, and the recovery yields of the target compounds will influence the results if not adequately corrected for. This is distinct from the IDMS method used by NMIJ. Compared with external or internal standard methods, IDMS generally delivers greater accuracy and precision. ${ }^{31)}$ Multiple factors, such as matrix effects and watersoaking time, can also be considered reasons for the difference between values.

\subsection{Evaluation of analytical performances of participants}

Performance was evaluated using two types of $z$-scores, one based on consensus values calculated from the analytical results reported by participants $(z)$ and one based on reference values obtained by the NMIJ $\left(z_{\mathrm{NMIJ}}\right)$.

$z$-Scores $(z)$ were calculated using Eq. $1^{20,21,32)}$ :

$$
z=\frac{x_{\mathrm{i}}-X}{N I Q R}
$$

where $x_{\mathrm{i}}$ and $X$ represent the results reported by each participant and the consensus value calculated from the participants' results, respectively, and NIQR represents a normalized interquartile range: $0.7413 \times($ quartile 3 -quartile 1$){ }^{33)}$

The $z_{\mathrm{NMIJ}}$ was calculated using Eq. 2 :

$$
z_{\mathrm{NMIJ}}=\frac{x_{\mathrm{i}}-X_{\mathrm{NMIJ}}}{S D_{\mathrm{R}}}
$$

where $X_{\mathrm{NMIJ}}$ represents the NMIJ reference value, and $S D_{\mathrm{R}}$ represents between-laboratory precision calculated using a modified Horwitz equation $^{21)}$ and $X_{\mathrm{NMI}}$. The results of each $z$-score were interpreted as follows ${ }^{20,32)}$ :

$z \leq|2|$ : satisfactory

$|2|<z<|3|:$ questionable

$|3| \leq z$ : unsatisfactory

As an example, the $z$ - and $z_{\mathrm{NMI}}$-scores in the $2017 \mathrm{PT}$, calculated using Eqs. 1 and 2, are illustrated in Fig. 3. Participants can evaluate their relative position against other participants using $z$-scores; however, the participant's $z$-score was influenced by the skill of the other participants. Thus, participants are advised to refer to the $z_{\mathrm{NMI}}$-score, which is based on the reference values

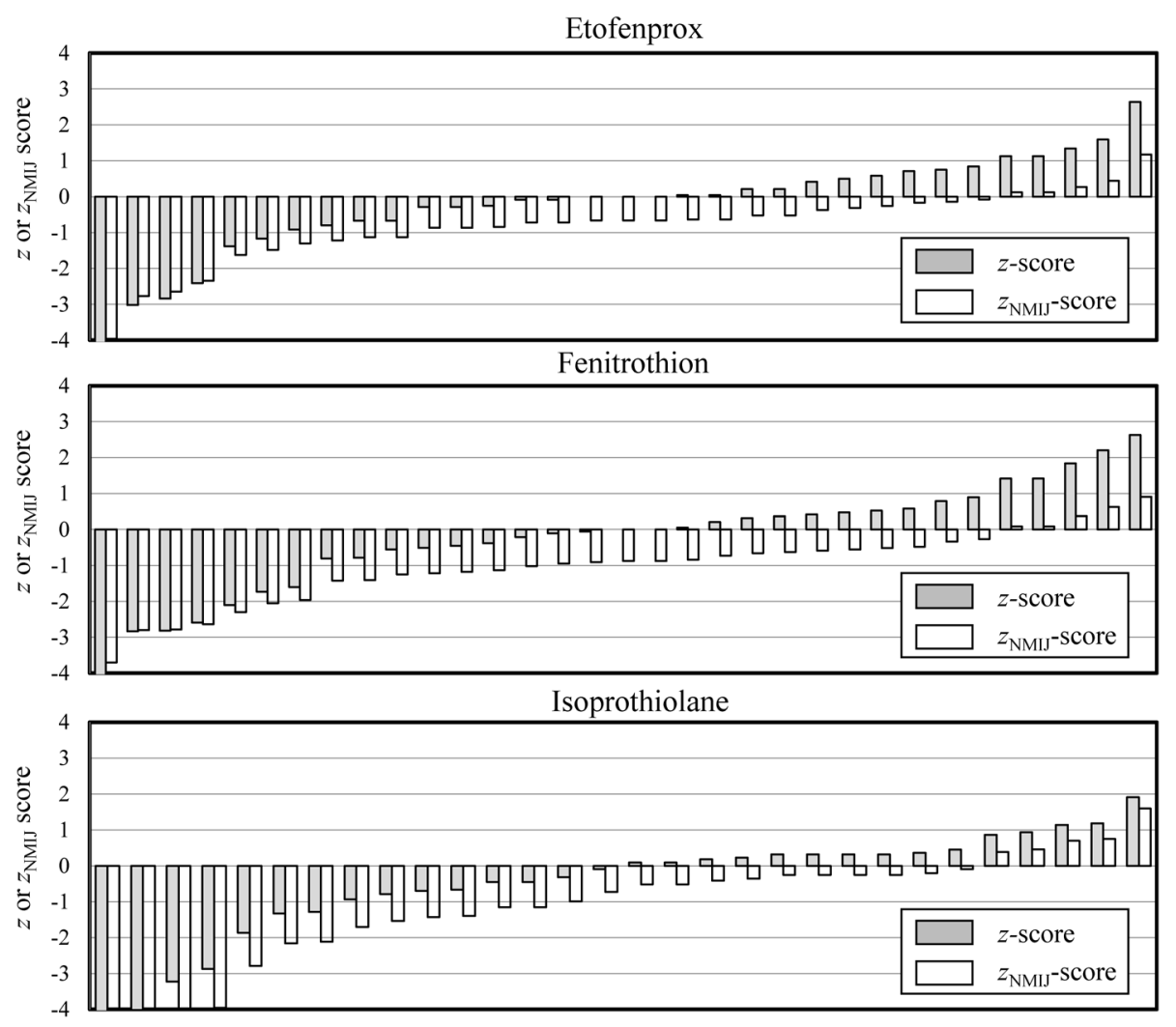

Fig. 3. Distributions of $z$ - and $z_{\mathrm{NMI}}$-scores for each target pesticide in the $2017 \mathrm{PT}$ (pesticides in brown rice). The $z$-scores were based on the consensus values calculated from the participant results. The $z_{\mathrm{NMIJ}}$-scores were based on the reference values provided by the NMIJ. 
with IDMS provided by the NMIJ.

For those participants whose results were questionable or unsatisfactory, the following problems were inferred from the reports submitted by participants (the details are also described in previous papers ${ }^{1,11,13)}$ ): (1) calculation errors; (2) errors in the unit conversion; (3) inappropriate calibration standard solutions; (4) quantification at a concentration lower than the quantification limit of one's method; (5) insufficient removal of interference in the clean-up process; (6) insufficient separation in GC or LC measurement; (7) inadequate maintenance of measurement instruments, such as GC/MS or LC/MS/MS; and/or (8) insufficient method validation.

\section{Concluding remarks}

NMIJ has developed CRMs and carried out PTs for the analysis of pesticide residues in food samples. CRMs have been developed based on international management system standards and have provided highly reliable certified values. Our CRMs are a useful tool for the validation of analytical methods and for quality assurance/quality control of pesticide residue analysis in foods. PTs have been conducted that allow participants to evaluate their analytical skills based on two $z$-scores: $z$ and $z_{\mathrm{NMIJ}}$. The $z_{\mathrm{NMIJ}}$ is effective for the evaluation of the accuracy of the analytical method used by each participant.

\section{Acknowledgements}

We are very grateful for this award. We are also very appreciative of those who recommended us and would like to thank the members of the Pesticide Science Society of Japan. We would like to thank the late Dr. Masako Ueji (Former president of the Japan Plant Protection Association), Dr. Toshiyuki Hobo (Former Professor, Tokyo Metropolitan University), Dr. Akemi Yasui (Food Research Institute, National Agriculture and Food Research Organization), Dr. Yoshitsugu Odanaka (Japan Association for Advancement of Phyto-Regulators), and Mr. Yuji Shimamura (Safety Research Institute for Chemical Compounds) for valuable discussions. We are very grateful to the laboratory members engaged in this study at NMIJ. We appreciate the cooperation of the participants for smooth implementation of PTs. A part of this work for CRM development was supported by the Research and Development Projects for Application in Promoting New Policy of Agriculture Forestry and Fisheries of the Ministry of Agriculture, Forestry and Fisheries, Japan (No. 21044).

\section{References}

1) T. Otake, T. Yarita, Y. Aoyagi, M. Numata and A. Takatsu: Evaluation of the performance of 57 Japanese participating laboratories by two types of z-scores in proficiency test for the quantification of pesticide residues in brown rice. Anal. Bioanal. Chem. 406, 7337-7344 (2014).

2) P. Araujo and L. Frøyland: Hierarchical classification designs for the estimation of different sources of variability in proficiency testing experiments. Anal. Chim. Acta 555, 348-353 (2006).

3) Y. Zhu, T. Kuroiwa, T. Narukawa, K. Inagaki and K. Chiba: Proficiency test in Japan for the elements in tea-leaf powder. Trends Analyt. Chem. 34, 152-160 (2012).

4) International Organization for Standardization: "ISO/IEC 17025: General requirements for the competence of testing and calibration laboratories," ISO, Geneva, Switzerland, 2017.
5) Codex Alimentarius Commission: "Guidelines for the assessment of the competence of testing laboratories involved in the import and export control of food CAC/GL 27-1997," Rome, Italy, 1997.

6) T. Otake, N. Itoh, Y. Aoyagi, M. Matsuo, N. Hanari, S. Otsuka and T. Yarita: Development of certified reference material for quantification of two pesticides in brown rice. J. Agric. Food Chem. 57, 8208-8212 (2009).

7) T. Otake, T. Yarita, Y. Aoyagi, Y. Kuroda, M. Numata, H. Iwata, K. Mizukoshi, M. Nakamura, M. Watai, H. Mitsuda, T. Fujikawa and H. Ota: Development of green onion and cabbage certified reference materials for quantification of organophosphorus and pyrethroid pesticides. J. Agric. Food Chem. 59, 8568-8574 (2011).

8) T. Otake, T. Yarita, Y. Aoyagi, Y. Kuroda, M. Numata, H. Iwata, M. Watai, H. Mitsuda, T. Fujikawa and H. Ota: Development of apple certified reference material for quantification of organophosphorus and pyrethroid pesticides. Food Chem. 138, 1243-1249 (2013).

9) T. Yarita, T. Otake, Y. Aoyagi, Y. Kuroda, M. Numata, H. Iwata, M. Watai, H. Mitsuda, T. Fujikawa and H. Ota: Development of soybean certified reference material for pesticide residue analysis. Talanta 119, 255-261 (2014).

10) T. Yarita, T. Otake, Y. Aoyagi, T. Kuroiwa, M. Numata and A. Takatsu: Proficiency testing for determination of pesticide residues in soybean: comparison of assigned values from participants' results and isotope-dilution mass spectrometric determination. Talanta 132, 269-277 (2015).

11) T. Otake, T. Yarita, T. Sakamoto, M. Numata and A. Takatsu: Proficiency testing for quantification of pesticide residues in treated brown rice samples: comparison of performance of japanese official multiresidue, modified QuEChERS, and QuEChERS methods. J. AOAC Int. 99, 821-829 (2016).

12) T. Yarita, T. Otake, Y. Aoyagi, M. Numata and A. Takatsu: Difference between consensus value of participants' results and isotope-dilution mass spectrometric results in proficiency testing for pesticide residues in husked wheat. Anal. Sci. 32, 557-563 (2016).

13) T. Otake, T. Yarita, Y. Aoyagi, N. Hanari and A. Takatsu: Proficiency testing by the National Metrology Institute of Japan for quantification of pesticide residues in grain samples from 2012 to 2018. J. Pestic. Sci. 44, 192-199 (2019).

14) P. De Bievre and H. S. Peiser: Basic equations and uncertainties in isotope-dilution mass spectrometry for traceability to SI of values obtained by this primary method. Fresenius J. Anal. Chem. 359, 523525 (1997).

15) T. J. Quinn: Primary methods of measurement and primary standards. Metrologia 34, 61-65 (1997).

16) W. Richter: Primary methods of measurement in chemical analysis. Accredit. Qual. Assur. 2, 354-359 (1997).

17) M. J. T. Milton and T. J. Quinn: Primary methods for the measurement of amount of substance. Metrologia 38, 289-296 (2001).

18) International Organization for Standardization: "ISO/IEC 17034: General requirements for the competence of reference material producers," ISO, Geneva, Switzerland, 2016.

19) International Organization for Standardization: "Guide 35: Reference materials-General and statistical principles for certification (3rd ed.)" ISO, Geneva, Switzerland, 2006.

20) International Organization for Standardization: "ISO/IEC 17043: Conformity Assessment-General Requirements for Proficiency Testing," ISO, Geneva, Switzerland, 2010.

21) International Organization for Standardization: "ISO 13528: Statistical methods for use in proficiency testing by interlaboratory comparison," ISO, Geneva, Switzerland, 2005. 
22) http://db.ffcr.or.jp/front/ (Accessed 18 May, 2021)

23) T. Yarita, T. Otake, Y. Aoyagi, N. Takasaka, T. Suzuki and T. Watanabe: Comparison of assigned values from participants' results, spiked concentrations of test samples, and isotope dilution mass spectrometric results in proficiency testing for pesticide residue analysis. J. AOAC Int. 101, 1199-1204 (2018).

24) https://www.bipm.org/utils/common/pdf/final_reports/QM/K95/ CCQM-K95.pdf (Accessed 18 May, 2021)

25) T. Yarita, A. Takatsu, K. Inagaki, M. Numata, K. Chiba and K. Okamoto: Matrix certified reference materials for environmental monitoring from the National Metrology Institute of Japan (NMIJ). Accredit. Qual. Assur. 12, 156-160 (2007).

26) Joint Committee for Guides in Metrology: "Evaluation of measurement data-Guide to the expression of uncertainty in measurement," JCGM 100, BIPM, Sèvres, France, 2008.

27) http://www.mhlw.go.jp/english/topics/foodsafety/positivelist060228/ dl/060526-1a.pdf (Accessed 18 May, 2021)

28) http://www.mhlw.go.jp/topics/bukyoku/iyaku/syoku-anzen/zanryu3/ siken.html\#3 (Accessed 18 May, 2021, in Japanese)
29) S. Hiramatsu, K. Nishiyama, S. Tokuhashi, T. Ashida, A. Kageyama, M. Takamiya, A. Nakamura, N. Takuma and K. Nishimori: Rep. Pub. Hlth. Kochi. 59, 47-52 (2013) (in Japanese).

30) M. Anastassiades, S. J. Lehotay, D. Stajnbaher and F. J. Schenck: Fast and easy multiresidue method employing acetonitrile extraction/ partitioning and "dispersive solid-phase extraction" for the determination of pesticide residues in produce. J. AOAC Int. 86, 412-431 (2003).

31) B. Binici, M. Bilsel, M. Karakas, I. Koyuncu and A. C. Goren: An efficient GC-IDMS method for determination of PBDEs and PBB in plastic materials. Talanta 116, 417-426 (2013).

32) M. Thompson, S. L. R. Ellison and R. Wood: The International Harmonized Protocol for the proficiency testing of analytical chemistry laboratories (IUPAC Technical Report). Pure Appl. Chem. 78, 145196 (2006).

33) K. Judprasong, P. Puwastien, J. Boonpor and N. Pinprapai: Laboratory performance on analysis of mandatory nutrients and preparation of nutrition labelling. Food Chem. 140, 598-607 (2013). 